\title{
Where Do We Stand and What Comes Next?
}

\author{
Sedigheh Rafiei Tabatabaei ${ }^{1^{*}}$ \\ ${ }^{1}$ Pediatric Infections Research Center, Department of Pediatric Infectious Diseases, Shahid Beheshti University of Medical Sciences, Tehran, IR Iran
}

\begin{tabular}{l}
\hline A R T I C L E I N F O \\
\hline Article type: \\
Editorial \\
\hline Article history: \\
Received: 06 Aug 2012 \\
Revised:12 Aug 2012 \\
Accepted: 17 Aug 2012 \\
Keywords: \\
Medicine \\
Publishing
\end{tabular}

All human societies have medical beliefs that provide explanations for birth, death, and diseases. Throughout history, illness has been attributed to magic, devils, or astral influence. The improvement of the medical sciences during the past millennium has modified or replaced superstitions in most cases (1).

More than three hundred years ago, medicine was in flux, with old beliefs in magical healing coexisting with notions of new treatments based on observation and evidence. In 1684, Medicina Curiosa, the first English-language medical journal was published in london (2).

The journals introduced a new theory. It was "a publication in which physicians could find the latest thoughts on subjects as diverse as diagnosis, treatment, and too many other things" (3).

The first U.S. medical journal "the Medical Repository" was established in 1797. One of the originators, a young New York physician, expressed that "this is no other than an endeavor to obtain an accurate and annual account of those general diseases which reign each season, over every part of the United States" (2).
Implication for health policy/practice/research/medical education:

This article focuses particularly on Iranian medical journals history to inform readers about the beginning and continuance of this procedure.

- Please cite this paper as:

Rafiei Tabatabaei S. Where Do We Stand and What Comes Next? Arch Pediatr Infect Dis.2013;1(1): 2-3. DOI: 10.5812/pedinfect.7927

Published by Kowsar Corp, 2013. cc 3.0.

The New England Journal of Medicine (NEJM) describes itself as the oldest continuously published medical journal in the world. The New England Journal of Medicine and Surgery was the first issue of the NEJM which was published in January 1812 (4).

In the year 1942, the publication of a monthly medical journal entitled "Naameh Daneshkadeh Pezeshki" or "medical college monthly letter", as the first Persian scientific journal in Iran was approved. The first issue of this journal was published in February-March $1942(5,6)$. The first Iranian English-language journal is The Iranian Journal of Medical Sciences (IJMS), which has been published since 1970 (7).

In 1900, many journals with content similar to current peer-reviewed articles and scientific reported studies were published. In the past few years, we have advanced from a sacristy of information to a surfeit (3).

\section{Why Do We Need to Publish a Medical Journal?}

We believe that access to high quality healthcare is a ba-

\footnotetext{
* Corresponding author: Sedigheh Rafiei Tabatabaei, Pediatric Infections Research Center, Department of Pediatric Infectious Diseases, Shahid Beheshti University of Medical Sciences, Tehran, IR Iran.Tel:+98-22226941, Fax:+98-22226941,E-mail:sr_tabatabaei@yahoo.com
} 
sic human right. The medical research centers empower healthcare workers by providing them with the information and resources that help them extend their knowledge and keep them up to date.

Another important thing is research collaboration. Communication is part of almost any professional activity. For researchers, writing scientific papers and publishing them in medical journals is a basic need to present their works for inter-institutional and international collaboration. We belief that, more collaboration is actually better, whether for the advancement of knowledge or for use the results of our scientific endeavors more effectively.

It is a fact, that quality of the journals is very important, and it is only as good as the articles they include. I think, regular publication with distribution along with an online edition is 'equally important' as the quality of the journals; and certainly, these key points provide a strong base to maintain and attract international authors to a journal. Archive of Pediatric Infectious Diseases (APID) is a clinical journal, which will be published quarterly in October, January, April and July.

This journal is informative to all practicing pediatric infectious diseasis specialists, immunologists and internists. The Journal context is devoted to particular compilation of the latest worldwide and interdisciplinary approach and findings including original manuscripts, meta-analysis and reviews, health economic papers, debates and consensus statements of clinical relevance of pediatric diseases field especially infectious diseases and immunology. In addition, consensus evidential reports will highlight the new observations, original researches and results accompanied by innovative treatments.

I hope with the help of our colleagues in the Pediatric Infections Research Center (PIRC), we would be able to take a small step towards publishing and spreading some valuable papers.

\section{Authors' Contribution}

None declared.

\section{Financial Disclosure}

None declared.

\section{References}

1. History of medicine 2012 [updated 2012; cited]; Available from: http://en.wikipedia.org/wiki/History_of_medicine.

2. Curious Medicine, the first English-language medical journal, mixed the technical with the practical. 2009 [updated 2009; cited]; Available from: http://protomag.com/assets/medicinacuriosa.

3. Kahn RJ, Kahn PG. The Medical Repository--the first U.S. medical journal (1797-1824). N Engl J Med.1997;337(26):1926-30.

4. Lawrence AK. THE DOCTOR'S WORL; Editor of Journal Envisions New Directions and Lighter Tone. The New York Times.1991.

5. Hadjitarkhani A. IRANIAN MEDICAL JOURNALS. RJMS. 1995(2):1.

6. Bahadori M, Azizi MH. The first medical journal of Tehran University. Arch Iran Med. 2007;10(3):420-3.

7. The Iranian Journal of Medical Sciences. [cited]; Available from: http://ijms.sums.ac.ir/site/about.aspx. 